\title{
Correlation between Microalbuminuria and Ultrasonographically Measured Carotid Intima Media Thickness in Type 2 Diabetic Subjects
}

TAHER MA ${ }^{\mathrm{a}}$, MALEK MA ${ }^{\mathrm{b}}$, RAHMAN N $^{\mathrm{c}}$, ABEDIN N $^{\mathrm{d}}$, SHEGUFTAF $^{\mathrm{e}}$, SHARIF MM $^{\mathrm{f}}$, RAHMAN MT ${ }^{\mathrm{g}}$

\begin{abstract}
:
Background: Microalbuminuria is associated with increased cardiovascular mortality in type 2 Diabetes mellitus. Carotid intima media thickness reflects index of cardiovascular disease. There is increased prevalence of microalbuminuria found in type 2 diabetes. So there is a positive correlation between microalbuminuria and carotid intima media thickness in type 2 diabetic subjects.

Objective: This study was performed to find out correlation between microalbuminuria and ultrasonographically measured carotid intima media thickness in type 2 diabetic subjects.

Materials and methods: The cross-sectional study was carried out in the Department of Radiology \& Imaging, BIRDEM from $1^{\text {st }}$ june 2011 to $31^{\text {st }}$ may 2012. A total number of 90 type 2 diabetic patients with microalbuminuria were included. All the subjects underwent $B$ mode sonographic imaging of the extracranial carotid arteries. The intima media thickness of both left and right side was recorded. Urinary albumin and creatinine were measured in random urine samples. The urinary albumin concentration was determined by turbidimetric immuneassay (TIA) with the use of superior microalbumin kit and creatinine was measured by Jaffe's reaction. Albumin-to-Creatinine Ratio (ACR) was calculated.
\end{abstract}

a. Dr. Md. Abu Taher, MBBS, M.Phil, MD, Associate Professor, Department of Radiology and Imaging, BIRDEM General Hospital, Dhaka.

b. Dr. Musarrat Abdul Malek, MBBS, M. Phil. Ex M phil student, Department of Radiology and Imaging, BIRDEM General Hospital, Dhaka.

c. Dr. Nayema Rahman, MBBS, M. Phil. Junior Consultant, Department of Radiology and Imaging, BIRDEM General Hospital, Dhaka.

d. Dr. Naffisa Abedin, MBBS, MD, Assistant professor, Department of Radiology and Imaging, BIRDEM General Hospital, Dhaka.

e. Dr. Farzana Shegufta, MBBS, MD, Junior Consultant, Department of Radiology and Imaging, BIRDEM General Hospital, Dhaka.

f. Dr. Md. Mofazzal Sharif, MBBS, MD Student, Department of Radiology and Imaging, BIRDEM General Hospital, Dhaka.

g. Dr. Md. Towhidur Rahman, MBBS, MD Student, Medical Officer, Department of Radiology and Imaging, BIRDEM General Hospital, Dhaka.

Address of Correspondence:Dr. Md. Abu Taher, MBBS, M.Phil, MD, Associate Professor, Department of Radiology and Imaging, BIRDEM General Hospital, Dhaka.

Received: 14 November 2012

Accepted: 09 July 2013
Results: The total number of patient was 90,male were 68 and female were 22 (Male female ratio was 3.09:1). Mean age was 55.6 years with standard deviation $(S D) \pm 6.06$ years (Range 45-65 years).The mean ACR was $78.9 \mathrm{mg} / \mathrm{g}$ with standard deviation(SD) $\pm 21.8 \mathrm{mg} / \mathrm{g}$ (Range 33 to $111 \mathrm{mg} / \mathrm{g}$ ). The mean intima-media thickness of carotid arteries was $1.04 \mathrm{~mm}$ with standard deviation (SD) $\pm 0.19 \mathrm{~mm}$. Significant positive correlation was found between albumin-to-creatinine ratio (ACR) and intima-media thickness of carotid arteries (CIMT) in type 2 diabetic subjects. The value of Pearson's correlation was $r=0.583$, which is significant $(p<0.01)$. Therefore, there was a linear positive correlation between albumin-tocreatinine ratio (ACR) and intima-media thickness of carotid arteries (CIMT) in type 2 diabetic subjects.

Conclusion:From this cross-sectional study it can be concluded that there is a significant positive correlation between microalbuminuria and ultrasonographically measured carotid intima media thickness in type 2 diabetic subjects.

Key words: Type 2 diabetic, microalbuminuria, ultrasonographically measured carotid intima media thickness.

(Birdem Med J 2013; 3(2): 85-89)

Introduction:

Microalbuminuria is associated with cardiovascular mortality in subjects with type 2 diabetes mellitus ${ }^{1}$ and cardiovascular disease accounts for $70 \%$ of the mortality associated with diabetes mellitus. ${ }^{2}$ In type 2 diabetes the prevalence of microalbuminuria is $20-25 \%$ in both newly diagnosed and established diabetes. Microalbuminuria is associated with components of the metabolic syndrome and as such is more inclined to excessive cardiovascular risk. ${ }^{3}$ Microalbuminuria shows a definite predisposition to macrovascular complications especially in type 2 diabetics and causes substantial morbidity and mortality from myocardial infarction, stroke, angina, cardiac failure and peripheral vascular disease. Carotid intima-media thickness (CIMT) has been significantly associated with advancing age, raised systolic blood pressure, erythrocyte sedimentation rate (ESR), glomerular filtration rate (GFR), LDL (Low Density Lipoprotein), cholesterol and microalbuminuria. ${ }^{3}$ 
Atherosclerosis is a chronic inflammatory response of the arterial wall characterized by intimal cellular proliferation and repetitive formation and organization of thrombi. Lesion progression occurs through the interaction of modified lipoproteins, monocyte-derived macrophages, and $\mathrm{T}$ lymphocytes with the normal cellular constituents of the arterial wall. An atheromatous plaque, which is the hallmark lesion of atherosclerosis, consists of a raised lesion with a soft, yellow, grumous core of lipid (mainly cholesterol and cholesterol esters) covered by a white fibrous cap. Studies show that carotid IMT has significant association with systolic blood pressure but not with diastolic blood pressure. ${ }^{4}$ Several studies have suggested the association of microalbuminuria and atherosclerosis, most notably the link between microalbuminuria and endothelial dysfunction. The assessment of carotid atherosclerosis by ultrasonographic measurement of carotid IMT took over as being the marker of atherosclerosis, when it was suggested by the International Atherosclerosis Project that the atherosclerotic process occurs at the same time in the carotid, the cerebral and the coronary arteries. Carotid IMT measurement heralded the availability of a highly accurate, reproducible, non-invasive, reliable and valid estimate of the arterial wall thickness and a useful tool for detecting and monitoring changes in intima media thickness and assessing sub-clinical atherosclerosis. Microalbuminuria predicts future cardiovascular disease risk in diabetic patients, in elderly patients, as well as in the general population. Whether albuminuria is a risk factor or just a marker for cardiovascular disease, it identifies the high-risk diabetic patient who should be targeted for early, aggressive intervention against proven risk factors. Epidemiological studies have shown an association between microalbuminuria and insulin resistance, obesity, salt sensitivity and dyslipidaemia in patients with essential hypertension and diabetes and an association with an excess of other cardiovascular risk factors. Endothelial dysfunction might promote increased penetration of atherogenic lipoprotein particles in the arterial wall, but glycaemic status, insulin resistance, procoagulant state and adhesion molecules have all been implicated in the pathogenesis of atherosclerosis. ${ }^{5}$ Yokoyama $^{6}$ have found that subclinical atherosclerosis is increased in type 2 diabetic patients with microalbuminuria and can be evaluated by carotid intima-media thickness (IMT); microalbuminuria is related to atherosclerosis at an early stage of the disease process, and is a significant determinant of carotid IMT independent of conventional cardiovascular risk factors in type 2 diabetic patients with no clinical nephropathy or any vascular diseases.

Previous studies have established that subclinical atherosclerosis is increased in type 2 diabetic patients with microalbuminuria. Carotid intima-media thickness (Carotid IMT) is a surrogate marker of atherosclerosis and imparts prognostic information independent of traditional cardiovascular risk factors. It has also developed as an important functional predictor of cardiovascular system. Moreover, in a specialized hospital like BIRDEM, carotid IMT may be conveniently measured in type 2 diabetic patients by non-invasive Bmode ultrasonography, an accessible, effective and noninvasive tool. Microalbuminuria precedes overt proteinuria and diabetic nephropathy and has been postulated to be involved in the pathogenesis of atherosclerosis in type 2 diabetic patients. Thus, the detection of atherosclerosis at the earliest preclinical stage can help in the prediction and diagnosis of asymptomatic vascular disease. To the best of our knowledge, no studies have focused on assessing the correlation of microalbuminuria and carotid intima-media thickness in type 2 diabetic patients in Bangladesh. In this view, this study aims to assess the correlation between microalbuminuria and carotid intima-media thickness in type 2 diabetic subjects.

\section{Methodology:}

This cross-sectional study was carried out in the Department of Radiology \& Imaging, BIRDEM (Bangladesh Institute of Research and Rehabilitation in Diabetes, Endocrine and Metabolic Disorders) for a period of one year. A total of 90 type 2 diabetic patients with microalbuminuria were included in the final analysis. All the selected subjects underwent B mode sonographic imaging of the extracranial carotid arteries. Demographic information was prospectively recorded and substantiated by means of inspection of medical records. Information included the subjects' age, sex, albumin-tocreatinine ratio (ACR). All sonographic measurement of carotid arteries were done by researcher at first and findings were confirmed by consultant radiologist, Department of Radiology and Imaging, BIRDEM who did not know patient's albumin status to eliminate bias. The intima-media thickness of both left and right side was recorded. Urinary albumin and creatinine were 
measured in random urine samples. The urinary albumin concentration was determined by turbidimetric immunoassay (TIA) with the use of superior microalbumin kit and creatinine was measured by Jaffe's reaction. Albumin-to-Creatinine Ratio (ACR) was calculated.

\section{Result:}

The mean age was 55.6 years with standard deviation (SD) \pm 6.06 years. Table I shows that the majority (33\%) of the patients were in the age range of $60-65$ years followed by $26 \%$ in the age range of $55-59$ years, $21 \%$ in the age range of $45-49$ and remaining $20 \%$ in the age range 50-54. In present study male patients were 68 $(75.6 \%)$ and $22(24.4 \%)$ were female patients. The mean ACR was $78.9 \mathrm{mg} / \mathrm{g}$ with standard deviation (SD) \pm 21.8 $\mathrm{mg} / \mathrm{g}$. The ACR ranged from 33 to $111 \mathrm{mg} / \mathrm{g}$. From table II it was seen that majority of patients $(56 \%)$ were in the albumin-to-creatinine ratio range of $80-111 \mathrm{mg} / \mathrm{g}$. $29 \%$ of the patients was in the albumin-to-creatinine ratio range of $55-79 \mathrm{mg} / \mathrm{g}$, and the remaining $16 \%$ in the albumin-tocreatinine ratio range of $33-54 \mathrm{mg} / \mathrm{g}$. Intima-media thickness of carotid arteries was divided into three groups. Intima-media thickness of carotid arteries ranged from 0.81 to $1.50(\mathrm{~mm})$. The maximum numbers $(41 \%)$ were found in the intima-media thickness of carotid arteries group of 0.90-0.99 (mm). The mean intima-media thickness of carotid arteries was $1.04 \mathrm{~mm}$ with a standard deviation (SD) $\pm 0.19 \mathrm{~mm}$. Sonographically measured intima media thickness of carotid arteries (carotid IMT) was tabulated in $\mathrm{mm}$ and albumin-to-creatinine ratio(ACR) was tabulated in $\mathrm{mg} / \mathrm{g}$. Significant positive correlation was found between albumin-to-creatinine ratio (ACR) and intima media thickness of carotid arteries(CIMT) in type 2 diabetic subjects. The value of Pearson's correlation coefficient was $r=0.583$, which is significant $(\mathrm{p}<0.01)$. Therefore, there was linear positive correlation between albumin-to-creatinine ratio (ACR) and intima media thickness of carotid arteries (CIMT) in type 2 diabetic subjects which is illustrated in the figure 1 .

\section{Table I}

Age distribution of the study subjects $(n=90)$ :

\begin{tabular}{lcc} 
Age (in year) & Number of Patients & Percentage \\
\hline $45-49$ & 19 & 21 \\
$50-54$ & 18 & 20 \\
$55-59$ & 23 & 26 \\
$60-65$ & 30 & 33 \\
Mean \pm SD & $(55.6 \pm 6.06)$ & \\
Range (Min-Max) & $(45-65)$ & \\
\hline
\end{tabular}

\section{Table II}

Distribution of the study subjects according to albumin-to-creatinine ratio $(A C R)(n=90)$ :

\begin{tabular}{lcc} 
ACR $(\mathrm{mg} / \mathrm{g})$ & Number of Patients & Percentage \\
\hline $33-54$ & 14 & 16 \\
$55-79$ & 26 & 29 \\
$80-111$ & 50 & 56 \\
Mean \pm SD & $(78.91 \pm 21.76)$ & \\
Range & $(33.0-111.0)$ & \\
\hline
\end{tabular}

\section{Table III}

Distribution of the study subjects according to Carotid intima-media thickness (CIMT) $(n=90)$ :

\begin{tabular}{lcc} 
Carotid IMT $(\mathrm{mm})$ & Number of Patients & Percentage \\
\hline $0.81-0.89$ & 18 & 20 \\
$0.90-0.99$ & 37 & 41 \\
$1.0-1.5$ & 35 & 39 \\
Mean \pm SD & $(1.04 \pm 0.19)$ & \\
Range & $(0.81-1.50)$ & \\
\hline
\end{tabular}

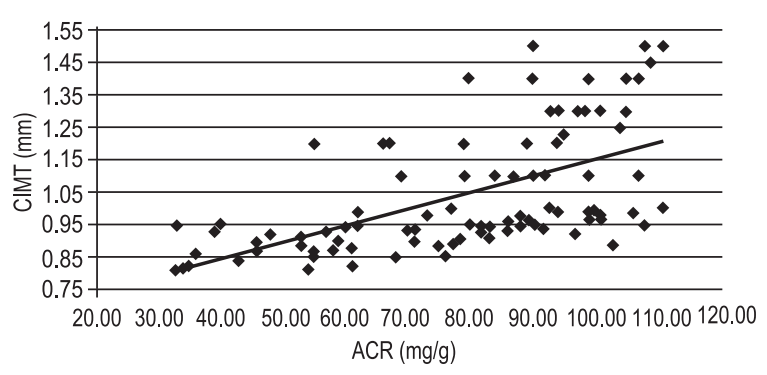

Fig.-1: Scatter diagram showing correlation between albumin-to-creatinine ratio (ACR) and intima media thickness of Carotid arteries(CIMT) $(n=90)$

\section{Discussion:}

The intima-media thickness (IMT) of extracranial carotid arteries provides an index of atherosclerosis in other vascular regions and has been shown to be associated with risk factors of atherosclerosis such as age, gender, hypertension, hyperlipidaemia etc. The noninvasive assessment of common carotid intima-media thickness (carotid IMT) is useful not only for epidemiological research but also for early detection of atherosclerosis related to stroke or coronary event. Measurement of carotid intima-media thickness (carotid IMT) by B mode 
color flow sonographic imaging is rapid, noninvasive and cost effective and is feasible in routine clinical practice. It also provides information to prove association of carotid intima-media thickness (carotid IMT) with risk profile of different patient groups and helps concerned clinician to make further decision in rational approach to patient management. This cross sectional study was done with an objective to find out the correlation between albumin-to-creatinine ratio (ACR) and ultrasonografically measured carotid intimamedia thickness (carotid IMT) in type 2 diabetic subjects. In this current study, it was observed that the mean $( \pm$ SD) age was $55.6 \pm 6.06$ years and majority $(33 \%)$ of the patients were in the age range $60-65$ years. Huang et al. $(2010)^{7}$ observed mean age in their study subjects and found the mean $\pm \mathrm{SD}$ age is $58.1 \pm 8$.1years with range from 29 to 76 years which is similar to the present study .Yokoyama et al. (2004) ${ }^{6}$ showed that the mean \pm SD age was $58 \pm 8$ years with range from $30-70$ years which is comparable with the present study. In this present study it was observed that $75.6 \%$ and $24.4 \%$ were male and female respectively and male female ratio was almost 3.09:1 which indicate that male patients were predominant in this study subjects and which is similar to the study of Diercks ${ }^{8}$ and Huang. ${ }^{7}$

In this study subjects were divided into three groups according to their albumin-to-creatinine ratio (ACR). The mean ACR was $78.9 \mathrm{mg} / \mathrm{g}$ with standard deviation (SD) $\pm 21.8 \mathrm{mg} / \mathrm{g}$. The albumin-to-creatinine ratio (ACR) ranged from 33 to $111 \mathrm{mg} / \mathrm{g}$. The majority of patients $(56 \%)$ were in the ACR ratio range of $80-111 \mathrm{mg} / \mathrm{g}, 29 \%$ of the patients were in the ACR ratio range of $55-79 \mathrm{mg} /$ $\mathrm{g}$, and the remaining $16 \%$ in the ACR range of $33-54 \mathrm{mg} /$ g. Yokoyama ${ }^{6}$ did a similar study and the subjects were classified by the tertile on the basis of their ACR, ranging from $44-105 \mathrm{mg} / \mathrm{g}$ with a mean of $60 \mathrm{mg} / \mathrm{g}$. The result obtained in the above study closely resembles the current study. On the basis of intima-media thickness of common carotid arteries (IMT), study subjects were divided into three groups. The mean \pm SD of intima-media thickness of carotid arteries was $1.04 \pm 0.19 \mathrm{~mm}$. Intimamedia thickness of carotid arteries ranged from 0.81 to $1.5 \mathrm{~mm}$. The majority ( $41 \%$ ) were found in the intimamedia thickness of carotid arteries group of 0.90-0.99 $\mathrm{mm}$, followed by $29 \%$ in the range $1.0-1.5 \mathrm{~mm}$ and remaining $20 \%$ between $0.8-0.89 \mathrm{~mm}$. Kawamoto ${ }^{9}$ did a study to investigate the relation between IMT and various factors. All the subjects were divided into three groups based on tertile of IMT. The authors mentioned that the bilateral carotid arteries were observed obliquely from the anterior and posterior directions. In another study, the investigators measured the thickness of the intima-media complex (IMT) on the far wall of the bilateral common carotid artery as the image at that site is more clearly compared with that of near wall as well as wall thickness near the $10 \mathrm{~mm}$ point of the $\mathrm{B}$ mode monitor, then used the mean value for analysis. (Sidhu ${ }^{10}$; Salonen ${ }^{11}$ ). A significant linear positive correlation $(\mathrm{r}=0.583 \mathrm{p}<0.01)$ was found between albumin-tocreatinine ratio (ACR) and intima media thickness of carotid arteries (CIMT) in type 2 diabetic subjects. This finding is similar to that of Yokoyama ${ }^{6}$, a study also done on type 2 diabetics, which showed a significant positive correlation $(r=0.26 ; p<0.0001)$ between albuminto-creatinine ratio (ACR) and intima-media thickness of carotid arteries (CIMT). Type 2 diabetic patients with microalbuminuria had a significantly higher value of IMT. Another study by Diercks ${ }^{8}$ found a statistically significant positive relationship $(\mathrm{r}=0.40, \mathrm{p}<0.001)$ between urinary albumin excretion and carotid intimamedia thickness (CIMT).

\section{Conclusion:}

This study was undertaken to find out the correlation between microalbuminuria and ultrasonographically measured carotid intima-media thickness in Type 2 diabetic subjects. The data obtained showed a significant positive correlation between microalbuminuria and ultrasonographically measured carotid intima-media thickness in Type 2 diabetic subjects.

\section{References:}

1. Mykkänen L., Zaccaro D.J., O'Leary D.H., Howard G., Robbins D.C., Haffner, S.M.. Microalbuminuria and Carotid Artery Intima-Media Thickness in Nondiabetic and NIDDM Subjects: The Insulin Resistance Atherosclerosis Study (IRAS). Stroke,1997; 28( 9): 1710-06.

2. Frier B.M., Fisher M. Diabetes mellitus. Colledge N.R., Walker B.R., Ralston S.H. Davidson's Principles and Practice of Medicine. $21^{\text {st }}$ edn ;2010: 824.

3. Mogensen C.E., Poulsen P.L. Epidemiology of microalbuminuria in diabetes and in the background population. Current Opinion in Nephrology and Hypertension. 1994; 3: 248-56. 
4. Nand N., Jain R., Seth S., Sen J., Sharma M. A new marker of Carotid atherosclerosis in middle aged adults: cystatin $\mathrm{C}$ or microalbuminuria. Indian Heart Journal.2010;62(4): 320-23.

5. Aftab S., Sudha V., Dixit U.S., Bairy K.L. A Correlation of Common Carotid Intima Media Thickness with Risk Factors for Atherosclerosis in Type 2 Diabetes Mellitus Patients. Indian Journal for the Practising Doctor. 2009; 5(6): 2009-12.

6. Yokoyama H., Aoki T., Imahori M., Kuramitsu M. Subclinical atherosclerosis is increased in type 2 diabetic patients with microalbuminuria evaluated by intima-media thickness and pulse wave velocity. Kidney International. 2004;66(1): 448-54.

7. Huang Y, Chen Y., Xu M., Gu M., Bi Y., Li X., Ning G. Low-Grade Albuminuria Is Associated with Carotid IntimaMedia Thickness in Chinese Type 2 Diabetic Patients.
The Journal of Clinical Endocrinology \& Metabolism. 2010;95(11): 5122-28.

8. Diercks G.F., Stroes E.S., Van Boven A.J., Van Roon, A.M., Hillege H.L., De Jong, P.E. et al. Difference in the Relation Between Urinary Albumin Excretion and Carotid Intima-Media Thickness in Nondiabetic and Type 2 Diabetic Subjects. Diabetes Care.2002; 25: 936-37.

9. Kawamoto R., Kajiwara T., Oka Y., and Takagi Y. An association between abdominal fat index and carotid atherosclerosis in women. J Atheroscier Thomb.2002; 9 : 213-18.

10. Sidhu P.S., Desai S.R. A simple and reproducible method for assessing intima-media thickness of common carotid artery. British Journal of Radiology.1997;70: 85-89.

11. Salonen R., Kaplan G.A., Salonen J.T., Lakka T A. Blood pressure and progression between carotid atherosclerosis in middle-aged man. Hypertension. 1999; 34: 51-56. 